\title{
Supervision Outcomes as Predictor to The Supervisory Relationship and Supervision Contextual Factors: Study on The Internship Trainee Counsellors
}

\author{
Nor Mazlina Ghazali ${ }^{a}$, Wan Marzuki Wan Jaafar ${ }^{b}$ and Azzahrah Anuar ${ }^{a}$ \\ a Department of Counselling, Faculty of Cognitive Sciences \& Human Development, \\ UniversitiMalaysia Sarawak \\ ${ }^{\mathrm{b}}$ Department of Counselor Education and Counselling Pyschology, Faculty of Educational Studies, \\ Universiti Putra Malaysia
}

\begin{abstract}
The purpose of this study was to investigate the influence of the supervisory relationship and contextual supervision factors on the supervision outcomes among trainee counsellors. Respondents were 120 trainee counsellors and 18 supervisors from four public universities in Malaysia. Eight instruments were used in measuring the variables. The Supervisory Working Alliance Trainee Inventory (SWAI-T) was administered to measure the supervisory working alliance among trainee counsellors and the Role Conflict Role Ambiguity Inventory (RCRAI) was administered to measure the role conflict among trainee counsellors. Meanwhile, the Supervision Interaction Questionnaire - Supervisee and Supervisor Inventory (SIQ-S) was used to measure the interaction between trainee counsellors and supervisor and the Counsellor Rating Form - Short (CRF-S) was used to measure the characteristics of the supervisors in supervision. The Selective Theory Sorter (STS) inventory was used to measure the counselling orientations among the trainee counsellors and supervisors whereas the Multicultural Counselling Knowledge and Awareness Scale (MCKAS) measures the knowledge and awareness toward multicultural counselling among trainee counsellors. The Supervision Outcomes Survey (SOS) and the Counsellor Performance Inventory (CPI) were utilized to measure the satisfaction and performance among trainee counsellors. Results have revealed that there was a significant correlation between the supervisory relationship (supervisees' working alliance, supervisees' role conflict, supervision interaction, supervisors' attributes) and supervision outcomes, $\mathrm{r}(118)=.53 ; \mathrm{p}<.05$. Other factors that have contributed to the significant correlations of supervision outcomes were supervisees' working alliance, supervisees' role conflict, and supervisors' attributes, $\mathrm{r}(120)=.55 ; \mathrm{p}<.05 ; \mathrm{r}(120)=$ $.21 ; \mathrm{p}<.05$; and $\mathrm{r}(116)=.50 ; \mathrm{p}<.05$ respectively. However, the result has shown that there was no significant correlation between the supervision contextual factors (supervisees' and supervisors' counselling orientation and supervisees' cultural knowledge and awareness) and supervision outcomes. The Multiple Regression analyses reported that the supervisory relationship had an influence on the supervision outcomes, $\mathrm{R}^{2}=.28, \mathrm{~F}$
\end{abstract}

\footnotetext{
${ }^{1}$ Corresponding author: wanmarzuki@upm.edu.
} 
$(1,105)=40.2, p<.05$. Meanwhile, the supervision contextual factors had no influence on the supervision outcomes. Based on the research findings, the model signified that the supervision process could bring out changes in the supervisees. Practically, the supervisees' working alliance was a significant factor that has influenced the supervisees' development. Therefore, the academic supervisor should consider the supervisees' role conflict, supervision interaction, and supervisors' attributes during supervision. It is recommended that the differences between supervision interaction of the supervisors and the supervisees are to be examined in the future research.

\section{Introduction}

Counselling supervision is one of the fundamental courses developed to monitor the counselling practices and to ensure that the existing counselling practices meet the standard professional requirement. Much attention has been given by the Board of Counsellors (Malaysia) to the curriculum of counselling education programme particularly the supervision process. It is imperative to provide a practical guideline in the supervision process to facilitate the supervisor and trainee counsellors' personal and professional development, promote their counselling competencies, and preserve the accountability of their practices. Therefore, the counselling educators have placed great emphasis on the supervision component in the counselling training programme especially in the practicum and internship courses.

Through supervision, trainee counsellors could improve self - development, enhance skills, implement therapeutic relationships, and protect the clients [23]. Supervisory relationships can be a positive form of working alliance between the trainee counsellors and supervisors because the supervision sessions have correlations with the satisfaction, performance, and supervisors' multicultural competence [16].

Supervision can be defined as a dynamic relationship in which a supervisor evaluates the trainee counsellors' performance or professional growth and competency in the clinical process [18]. The purpose of supervision focuses more on the therapeutic growth rather than the clients [5]. Evidently, the role of the supervisor in supervision has an influence on the supervisory relationship.

Supervisory relationship and supervision contextual factors determine the supervision outcomes. There is no distinct research that explains variables that emphasize on the supervision process or outcomes such as the pre and post supervision satisfaction [17]. Conceptually, the supervision outcomes are beneficial for researchers in managing and conceptualising the supervision experience holistically.

\section{Supervisory Relationship}

The supervisory relationship involves the relationship between the supervisor and trainee counsellors. The supervisory relationship comprises of the component of power and authority, the role of a trainee counsellor's and supervisor's values, issues of trust between trainees and their supervisors, and conflicts between supervisor and supervisee (Haynes et al., 2002). Supervisors may train their supervisees to effectively deal with a range of challenges, such as coping with doubts and fears, recognizing personal needs, recognizing countertransference, and understanding diverse value systems of clients. The foundation of supervision is the relationship between supervisor and trainee counsellors. The supervision 
process is an important indicator of a good professional relationship. Supervision is an educative process whereby the supervisee learns certain specific knowledge and skills.

The supervisory relationship component includes the supervisee's working alliance, role conflict, supervision interaction, and supervisor's attributes. The working alliance is correlated with the therapeutic relationship between the counsellor and the client [3].The supervisory working alliance is a collaborative process achieved based on the mutual agreement concerning the goals and tasks of supervision, as well as the development of a strong emotional bond [3]. Research has found that a strong supervisory working alliance signified a high supervisory satisfaction. For example, if the supervisory working alliance were positive, it is highly likely that the trainee counsellor would be more satisfied with the supervision process. Bordin et. al [3] emphasised on the importance of working alliance for a therapeutic supervisory relationship. The supervisory working alliance is a proposed primary concept in the supervisory relationship which result in the effectiveness of supervision [22].

The study also examined the influence of supervisees' role conflicts on the supervision outcomes. Supervisees at the advanced stage have tendency to involve with disagreement with their supervisors. They might be having conflicts with the supervisor due to the inconsistency evaluation and feedback from the supervisor. Role conflict is related with the negative self-statement and poor performance. Previous research has indicated that a high score in role conflict might be correlated with low satisfaction and poor performance among trainee counsellors. Role conflict is related to the negative self-statements which can lead to anxiety and low performance in supervision [9].

Another related variable in a supervisory relationship is supervision interaction. The supervision interaction revolves around control and conflict which demands power struggle and involvement between supervisor and trainee counsellor. The interaction can be assessed from the supervisor and trainee counsellor's perspectives. Power creates impact on the supervision outcomes such as satisfaction and performance. Green and Dekkers [10] also indicated that power has a direct or indirect influence on the outcomes of supervision. The ineffective management of the components in the supervisory relationship between supervisor and trainee counsellors might lead to negative outcomes. Previous literatures have reported about the link between the use of power in formal or informal supervision and the supervision outcomes. According to Quarto et. al [20] the supervisory interaction can be distinguished by the level of response from each person on behaviours indicative of power or submission and friendliness or hostility in the dyad relationship. Even though the supervisor has the formal power during the supervision process, it still requires the interaction between supervisor and trainee counsellors.

The characteristics of supervisors or supervisors' attributes consist of a sense of humour, empathy, respect, genuineness, personal warmth, supportive attitudes, ability to confront, immediacy, concern for supervisee's growth, and well-being of clients' welfare (Resources from power point slide issues of supervision). In addition, according to Ladany and Bradley, [17], the supervisors' attributes are described as the commitment shown by the supervisor during counselling and supervision. The supervisors' attributes include the alertness of the supervisor on the trainee counsellors' growth or progress as well as their well being [17] The criteria for choosing supervisor includes the level of competency and achievement in the helping activities [17]. 


\section{Supervision Contextual Factors}

Supervision contextual factors are categorized as the supervisor's and supervisees' counselling orientations and supervisees' cultural knowledge and awareness. The following are the descriptions of these constructs. Previous literatures have reported that there was a positive supervision outcome when the trainee counsellor has been equipped with the knowledge and awareness of culture of the clients. According to Buchanan (2006), supervisors' lack of multicultural competence has been quite alarming resulting in the lack of multicultural competence among trainee counsellors. The cultural competence awareness is salient because the supervisees typically have direct contacts with the clients. Moreover, the clinical supervision is crucial for the supervisees' professional growth and development in multicultural counselling skills [4]. An effective supervision generates a transformation in the trainee counsellor's in terms of gaining a holistic understanding and capability in working with the clients from various cultural background (Buchanan, 2006). The theoretical orientation could keep the supervisor and supervisees on the right track while managing the supervision and counselling process.

Counselling orientation is referred to as the supervisees' preferred theories or approaches. The supervisees are likely to perform when applying their own preferred theories [13]. A study on the clients' perception of the appropriateness of the orientation of the counsellor and the client has generated a successful outcome of the therapy and became a unique contributor to the supervision outcome [12]. Hence, using similar principle, this study has investigated the relationship between the supervisor's and supervisees' counselling orientation. Contextual variables have to be considered when determining the satisfaction of trainee counsellors during supervision process including the counselling orientation of both parties, supervisors and trainee counsellors. The interaction of counselling orientation also affects the perceptions of supervisors [19].

The supervisees' cultural knowledge and awareness have typically focused on gender, ethnicity, race, sexual orientation, religious beliefs, and personal values. Cultural diversity in the supervision has been linked with the supervisees' satisfaction and supervision's outcomes in the previous research (Gatmon et al., 2001; Inman [16]; Murphy \& Wright, 2005 as cited in Green \& Dekkers, 2010). When the supervisors are competent in valuing the cultural diversity of the supervisees, it increases the supervisees' satisfaction.

\section{Supervision Outcomes}

Supervision outcomes are described as the composition of supervisor external events, supervisor characteristics, supervisee characteristics of supervision, and supervisee external events during the supervision process (Bradley \& Ladany, 2001). The Supervision Outcomes Survey (SOS) and Counsellor Performance Inventory (CPI) were used to gather the information on the supervision outcomes (supervisees' satisfaction and performance). The SOS measures the supervisee's satisfaction [24] whereas the CPI (Iannelli, 2000) measures the supervisees' performance Supervisee's satisfaction and performance are defined as the trainee counsellors' ideas on the common quality of supervision experiences related to the individual motivational and practical needs (Ladany et al., as cited in Madani et al., 2010). Setting a high standard in the evaluation process, using indirect forms of communication, and emphasizing shortcoming were among reasons that have contributed to the poor supervision experienced by the family therapy trainee counsellor's (Anderson et al., 2000). On the other hand, the presence of a helpful supervisor in the supervision has been perceived as a good supervision experience because it is a supervisory relationship that promotes sensitivity in accommodating the needs of the counsellors-in-training [14]. Based on the findings of this study, it can be inferred that the supervisees' satisfaction and 
performance were related with the trainee counsellors' perception of the general quality of the supervision process of which contributes to motivation and the importance of the facilitative relationship in the professional development of trainee counsellors.

Performance is an important component in determining the clients' feelings, counsellors' interests, listening skills, and as well as counsellors' competency in counselling technique because these characteristics influence outcomes of the supervision process [11]. Performance might generation useful information such as understanding personal satisfaction of supervisees in the supervision process (Ilgen, et. al, as cited in Fried \& Tiegs, 1995).

\section{Trainee Counsellors or Supervisees}

A trainee counsellor is an individual seeking licensure as a professional counsellor. Trainee counsellors are those who are at the final stage of the study programme who spend considerable time at the designated site(s) (Robert, 2001). The trainee counsellors were the selected undergraduate students who were in their final year of study in the counselling programme and were undergoing an internship either at the agency, school, or hospital setting.

\section{Methodology}

This research utilizes a quantitative design to measure the supervisory relationship and supervision contextual factors on the supervision outcomes. The instruments that have been administered include the Supervisory Working Alliance Inventory - Trainee version (SWAI-T) with 19 items, Role Conflict Role Ambiguity Inventory (RCRAI) with 12 items, Counsellor Rating Form Short (CRF-S), and Supervision Inventory Questionnaire (SIQ).

The CRF-S is a 12-item instrument consist of three components which include attractiveness, expertness, and trustworthiness whereas the SIQ - Supervisee and SIQ Supervisor is a 20 -item instrument that assesses the supervisees and supervisors' interaction and its influence on the supervision outcomes. Meanwhile, the supervision contextual factors are measured using the Selective Theory Sorter (STS), a 60-item instrument.

Other instruments that have been administered in the study were as follows: The Multicultural Counselling Knowledge and Awareness Scale (MCKAS) with 32 items, the Supervision Outcomes Survey (SOS), and the Counsellor Performance Inventory (CPI).

\section{Section A: Demographic Information}

In this section, respondents were required to respond to the demographic information including gender, races, level of education, year of study, and setting of internship or practicum.

\section{Section B: Supervisory Relationship measures}

To measure the supervisory relationship, the following instruments were administered: (i) the Supervisory Working Alliance Inventory - Supervisee version (SWAI-T), (ii) the Role Conflict Role Ambiguity Inventory (RCRAI), (iii) the SIQ - supervisor and SIQ supervisees inventory, and (iv) the Counsellor Rating Form - Short (CRF-S). 


\section{Pilot Study}

The purpose of a pilot test is to design a new research field in determining the variables that are measureable with different tests and conditions (Dell et al., 2000). There are no specific number of respondents in the pilot test, however, they rely on the researcher's experience or fieldwork, because there is no prior data on the particular research. Data from the pilot tests are seldom used to determine the sufficiency of variables of the research.

\section{Validity and Reliability}

The content validation has been conducted by the experts specializing in counselling with a vast experience in the counselling practice. The evaluation and rating by the experts were useful to ensure the accuracy of the content of each instrument. 25 counselling interns and 25 supervisors at a higher education institution in Malaysia were recruited as sample of the study. Seven male and 18 female counselling interns as well as 19 male and six female supervisors participated in the pilot study. They were identified based on the list gathered from the internship coordinator. During the pilot test, they were in the midst of the internship process. The respondents answered all the questions within one month. The Cronbach alpha from $\alpha=0.61$ to $\alpha=0.97$ were reported in the study.

\subsection{Participants}

Respondents of the research were 120 counselling who undergo the internship at organisations. Respondents were required to rate the scale on each measures involved. The sample consisted of 19.2 percent males $(\mathrm{N}=23)$ and 80.8 percent females $(\mathrm{N}=97)$. Majority of the respondents were females (Table 1). Ethnically, there were 75.8 percent Malays $(\mathrm{N}=91), 8.3$ percent Chinese $(\mathrm{N}=10)$, followed by 2.5 percent $(\mathrm{N}=3)$ Indians and 13.3 percent were from other ethnic groups (i.e: Dusun, Bajau, Iban, Bidayuh, Melanau). Malay respondents formed the majority (Table 1). As for the supervisors' ethnic background, Malays made up 66.7 percent of the sample $(\mathrm{N}=12) .16 .6$ percent $(\mathrm{N}=3)$ were Chinese, and 16.6 percent $(\mathrm{N}=3)$ were from other ethnic groups (i.e; Dusun, Murut, Iban, and Bidayuh). The highest degree level attained by the supervisors were the M.A/M.Ed/M.Sc (55.6\%) and 44.4 percent PhD/Ed.D.

Table 1: Descriptive Information on the Demography of the Trainee Counsellors and Supervisors

\begin{tabular}{|l|c|c|}
\hline Descriptive information & Frequency & Percent \\
\hline Gender of Trainee Counsellors & 19.2 \\
\hline Male & 23 & 80.8 \\
\hline Female & 97 & 100.0 \\
\hline Total & 120 & \\
\hline \multicolumn{2}{|l}{} \\
\hline Etnnicity of Trainee Counsellors \\
\hline Malay & 91 & 75.8 \\
\hline Chinese & 10 & 2.3 \\
\hline Indian & 3 & 13.3 \\
\hline Others & 16 & 100.0 \\
\hline Total & 120 & \\
\hline
\end{tabular}




\begin{tabular}{|c|c|c|}
\hline \multicolumn{3}{|c|}{ Supervisors' Ethnicity } \\
\hline Malay & 12 & 66.7 \\
\hline Chinese & 3 & 16.6 \\
\hline Others & 3 & 16.6 \\
\hline Total & 18 & 100.0 \\
\hline \multicolumn{3}{|c|}{ Highest degree level attained by supervisors } \\
\hline M.A/M.Ed/MSc. & 10 & 55.6 \\
\hline PhD/Ed.D & 8 & 44.4 \\
\hline Total & 18 & 100.0 \\
\hline
\end{tabular}

\subsection{Data Collection and analysis}

Data of the research were analysed by the IBM Statistical Programme Social Sciences (SPSS) Version 23.0. Descriptive and inferential analyses were used in the data analysis. The descriptive analyses were used to analyse the demographic factors. The inferential analyses were used to analyze the supervisory relationship (supervisees' working alliance, supervisees' role conflict, supervision interaction, and supervisors' attributes) and supervision contextual factors (supervisors' and supervisees' counselling orientation and supervisees' cultural knowledge and awareness) and how these variables might relate and influence the supervision outcomes (supervisees' satisfaction and performance). Correlation coefficient and multiple regression were appropriate for measuring various types of issues in the behavioural research (Cohen \& Cohen, 1983, Pedhazur, 1982; Mc Neil et al., 1975 and Ward \& Jennings, 1973). Therefore, the Pearson product moment correlation coefficient and Multiple Regression analysis tests were chosen to analyse the data.

\section{Finding}

In this research, each independent variable is described as the supervisory relationship. Table 2 reports the descriptive statistics of the supervisory relationship. Results on the independent variables are as follows: supervisees' working alliance $(\mathrm{M}=99.87, \mathrm{SD}=$ 21.14); rapport $(M=67.48, S D=14.91)$ which was higher than the mean score of client focus $(\mathrm{M}=32.39, \mathrm{SD}=6.73)$; supervisees' role conflict $(\mathrm{M}=49.00, \mathrm{SD}=8.60$; $)$; supervision interaction $(\mathrm{M}=137.90, \mathrm{SD}=18.38)$; supervisees' control $(\mathrm{M}=28.90, \mathrm{SD}=$ 9.67) had a higher score than the supervision conflict $(\mathrm{M}=14.01, \mathrm{SD}=5.38)$, and the supervisors' control $(\mathrm{M}=24.55, \mathrm{SD}=5.20)$. Results on the supervisors' perceptions revealed the supervisors' control $(\mathrm{M}=37.42, \mathrm{SD}=8.21)$ had a higher score than the supervision conflict $(\mathrm{M}=34.01, \mathrm{SD}=9.11)$; supervisors' attributes $(\mathrm{M}=71.58, \mathrm{SD}=$ 10.89); trustworthiness $(\mathrm{M}=24.11$ and $\mathrm{SD}=3.88)$ showed a higher score then expertness $(\mathrm{M}=24.03, \mathrm{SD}=3.48)$ and attractiveness $(\mathrm{M}=23.08, \mathrm{SD}=5.18)$ and supervision contextual factors (supervisors' and supervisees' counselling orientation $(\mathrm{M}=655.31, \mathrm{SD}=$ 47.51) and supervisees' cultural knowledge and awareness $(\mathrm{M}=140.58, \mathrm{SD}=24.11)$; supervisees' cultural knowledge was $(\mathrm{M}=87.34, \mathrm{SD}=15.45)$, and supervisees' awareness was $(\mathrm{M}=43.87, \mathrm{SD}=8.12)$.

Table 2: Description on means and standard deviations of independent variables 


\begin{tabular}{|c|c|c|c|}
\hline Scales & $\mathrm{n}$ & $\begin{array}{l}\text { Mean } \\
(M)\end{array}$ & $\begin{array}{c}\text { Standard Deviation } \\
(S D)\end{array}$ \\
\hline \multicolumn{4}{|l|}{ Supervisory Relationship } \\
\hline SWA & 120 & 99.87 & 21.14 \\
\hline Rapport & 120 & 67.48 & 14.91 \\
\hline Client Focus & 120 & 32.39 & 6.73 \\
\hline SRC & 119 & 49.00 & 8.60 \\
\hline SI & 116 & 137.90 & 18.38 \\
\hline Supervisee Control & 119 & 28.90 & 9.67 \\
\hline $\begin{array}{l}\text { Supervision Conflict - } \\
\text { Supervisee }\end{array}$ & 117 & 14.01 & 5.38 \\
\hline $\begin{array}{l}\text { Supervisor Control - } \\
\text { Supervisee }\end{array}$ & 119 & 24.55 & 5.20 \\
\hline $\begin{array}{l}\text { Supervisor Control - } \\
\text { Supervisor }\end{array}$ & 120 & 37.42 & 8.21 \\
\hline $\begin{array}{l}\text { Supervision Conflict - } \\
\text { Supervisor }\end{array}$ & 120 & 34.01 & 9.11 \\
\hline F & 118 & 71.58 & 10.89 \\
\hline Attractiveness & 120 & 23.08 & 5.18 \\
\hline Expertness & 120 & 24.03 & 3.48 \\
\hline Trustworthiness & 118 & 24.11 & 3.88 \\
\hline \multicolumn{4}{|l|}{ Supervision Contextual Factors } \\
\hline SSCO & 94 & 655.31 & 47.51 \\
\hline SCKA & 116 & 140.58 & 24.11 \\
\hline Knowledge & 119 & 87.34 & 15.45 \\
\hline Awareness & 118 & 43.87 & 8.12 \\
\hline
\end{tabular}

*SWA - supervisory working alliance; SRC - supervisees' role conflict; SI - supervision interaction; SA - supervisors' attributes; SSCO - supervisor and supervisees' counselling orientation and SCKA - supervisees' cultural knowledge and awareness.

The correlations between the supervisory relationship (supervisees' working alliance, supervisees' role conflict, supervision interaction, and supervisors' attributes) and supervision outcomes were analysed using the Pearson product moment correlation coefficient. The sample respondents were trainee counsellors who were undergoing the internship programme at the organisations. Based on Cohen (1992) formula, the minimum sample to conduct the analysis in this study was 85 . The output showed that the supervisory relationship (supervisees' working alliance, supervisees' role conflict, supervision interaction, and supervisors' attributes) had a coefficient $r=.53$, which was significant at $p<.05$ (Table 3). As a conclusion, the supervisory relationship was related to the supervision outcomes. Based on the result, the null hypothesis was rejected. 
Table 3: Pearson product moment correlation coefficient of supervisory relationship and supervision outcomes.

\begin{tabular}{|l|l|l|}
\hline Scales & r & Sig. \\
\hline SR & .53 & .00 \\
& & \\
\hline SO & 1.00 & .00 \\
\hline
\end{tabular}

* SR = Supervisory Relationship; $S O=$ Supervision Outcomes

Based upon the Pearson product moment correlation coefficient test results, the supervision contextual factors (supervisors' and supervisees' counselling orientation and supervisees' cultural knowledge and awareness) were not significantly correlated with the supervision outcomes, $r=.18$ at $\mathrm{p}>.06$. As a conclusion, the independent variable was not related to the dependent variable. Therefore, the null hypothesis was accepted (Table 4).

Table 4: Pearson product moment correlation coefficient of supervision contextual factors (supervisors' and supervisees' counselling orientation and supervisees' cultural knowledge and awareness) and supervision outcomes.

\begin{tabular}{|l|l|l|}
\hline Scales & r & Sig \\
\hline SCF & .18 & .00 \\
& & \\
\hline SO & & \\
\hline
\end{tabular}

A stepwise Multiple Regression analysis was conducted to investigate whether the supervisory relationship and supervision contextual factors influenced the supervision outcome. The prediction model contained two predictors. The correlations were statistically significant $\mathrm{F}(1,105)=40.2, \mathrm{p}<.05$, and accounted for approximately 28 percent of the variance of the supervision outcome $\left(R^{2}=.28\right.$, Adjusted $\left.R^{2}=.27\right)$. Supervision outcome was primarily influenced by the higher level of supervisory relationship and lower level of Supervision Contextual Factors. Supervisory relationship highly accounted for approximately 53 percent of the variance in supervision outcome but supervision contextual factors accounted for only 7.8 percent of the variance of supervision outcome. The regression equation for predicting the supervision outcome is as follows: Predicted supervision outcome $=(0.85)$ supervision outcomes $+(-0.22)$. Therefore, the null hypothesis was rejected. Therefore, the supervisory relationship predicted the supervision outcomes. However, the supervision contextual factors did not predict the outcomes of supervision. Details on this description are in Table 5. 
Table 5: Influence of supervisory relationship and supervision contextual factors on supervision outcomes.

\begin{tabular}{|l|c|c|c|c|c|c|}
\hline Predictor & $\mathrm{b}$ & SE-b & Beta & Pearson $\mathrm{r}$ & $\mathrm{sr}^{2}$ & $\begin{array}{c}\text { Structure } \\
\text { Coefficient }\end{array}$ \\
\hline $\begin{array}{l}\text { SO } \\
\text { (Constant }\end{array}$ & -.22 & 3.33 & .00 & 1.0 & .00 & .00 \\
\hline SR & .85 & .13 & .53 & .53 & .28 & .53 \\
\hline SCF & .00 & .00 & .07 & .20 & .01 & .00 \\
\hline
\end{tabular}

$* \mathrm{SO}=$ Supervision Outcomes; $\mathrm{SR}=$ Supervisory Relationship; Supervision Contextual Factors

\section{Conclusion and Implications}

The supervisory relationship had the highest influence on the supervision outcomes in this study. In the supervisory relationship, the supervision working alliance has contributed greatly to the supervision outcomes compared to other variables identified in the study. However, the supervision contextual factors did not significantly influence the supervision outcomes.

Implications from this research can be seen from the contributing factors that influenced the supervision outcomes which are of concern to the supervisors, trainee counsellors, universities, site supervisors, as well as the Counselling Board (Malaysia). Factors that have contributed towards positive supervision outcomes were the supervisees' working alliance, supervisees' role conflict, supervision interaction, and supervisors' attributes. These factors are statistically proven through this research.

Based on the current research, it is recommended that future researchers are to include the variable of cultural knowledge and awareness from the supervisor's perspectives. In addition, the additional explanation on the supervision contextual factors and the difference of supervision interaction between supervisor and trainee counsellor by the researcher are highly encouraged because it will help the respondents to understand the questions.

Place the figure as close as possible after the point where it is first referenced in the text. If there is a large number of figures and tables it might be necessary to place some before their text citation.

\section{References}

1. Anderson, S., A., Schlossberg, M., \& Rigazio -DlGillio, S., Family therapy trainees' evaluations of their best and worst supervision experiences. Journal of Marital and Family Therapy, 26, 79-91, (2000)

2. Bordin, E.S., The generalizability of the psychoanalytic concept of working alliance. Psychotherapy: theory, research, and practice, 16, 252-260, (1979)

3. Bordin, E., S., A working alliance based model of supervision. The Counselling Psychologist, 11, 35-42, (1983) 
4. Buchanan, G., F., The multicultural supervisor competency indicator: a behaviorally anchored rating scale approach. $\mathrm{PhD}$ Dissertation. Southern Illinois University Carbondale, (2006)

5. Cheon, H.S., Blumer, M. L.C., Shih, A.T., Murphy, J.M., \& Sato, M., The influence of supervisor and supervisee matching, role conflict, and supervisory relationship on supervisee satisfaction. Journal of Family Therapy, 31.52-67.doi 10.1007/s10591-008-9078-y, (2008)

6. Cohen, J., Quantitative methods in psychology: A power primer. Psychological Bulletin, 112(1), 155-159, (1992)

7. Cohen, J., Applied multiple regression/ correlation analysis for the behavioral sciences. Hillsdale NJ:Erlbaum, (1983)

8. Fried, Y. \& Tiegs. Supervisors' role conflict and role ambiguity differential relations with performance ratings of subordinates and the moderating effect of screening ability. Journal of Applied Psychology, (2), 282-291, (1995)

9. Friedlander, M., L., Keller, K., E., \& Peca-Baker, P., T., A., Effects of role conflict on counsellor trainees' self-statement, anxiety level, and performance. Journal of Counselling Psychology, 33, 74-77, (1986)

10. Green, M., S., \& Dekkers, T., D., Attending to power and diversity in supervision: An exploration of supervisee learning outcomes and satisfaction with supervision. Journal of Feminist Family Therapy, vol. 22, 293-312, (2010)

11. Grigg, A. E., \& Goodstein, L. D. The use of clients as judges of the counselors performance. Journal of Counseling Psychology, 1957, 4, 31-36.

12. Grunebaum, What if family therapy were a kind of psychotherapy? A reading of handbook of psychotherapy and behaviour change. Journal of Marital and Family Therapy, 14, 195-199, (1988)

13. Hill, C.E., Charles, D., \& Reed, K., G., A longitudinal analysis of changes in counselling skills during doctoral training in counselling psychology. Journal of Counselling Psychology, 28, 428 - 438, (1981)

14. Hutt, C. H., Scott, J., \& King, M., A phenomenological study of supervisees' positive and negative experiences in supervision. Psychotherapy: Theory, Research, and Practice, 20, 118-123, (1983)

15. Iannelli, R. J., A structural equation modeling examination of the relationship between counseling self-efficacy, counseling outcome expectations, and counselor performance. Unpublished doctoral dissertation, University of Missouri-Kansas City, (2000)

16. Inman, A.G., Supervisor multicultural competent and its relation to supervisory process and outcome. Journal of Marital and Family Therapy, 32, 73-85, (2006)

17. Ladany, N., \& Bradley, J., B., Counselor Supervision. Taylor \& Francis: New York, (2010)

18. Liddle, H., \& Saba, G., Teaching family therapy at the introductory level: A conceptual model emphasizing a pattern, which connects training and therapy. Journal of Marital and family Therapy, 8, 63-72, (1982)

19. Putney, Worthington, Jr and McCullough, Effects of supervisor and supervisee theoretical orientation and supervisor-supervisee matching on interns' perceptions of supervision. Journal of Counselling Psychology, vol. 39 (2), 258-265, (1992)

20. Quarto, C. J., Supervisors' and supervisees' perceptions of control and conflict in counselling supervision. The Clinical Supervisor. 21, $21-37$. Retrieved on 6 January, 2013 from http://www.gallaudet.edu/documents/academic/cou_supervisionmodels[1].pdf, (2002) 
21. Roberts, Walter, B., Jr., Morotti \& Allan, A., Professional School Counseling, 4 (3), 208-Retrieved from http://eric.ed.gov/?id=EJ630582 - 10k, (2001)

22. T Thome, S., Effects of working alliance on trainee counseling skills and personal development. PhD Dissertation. University of Nevada, Reno, (2006)

23. Tromski-Klingshrim, D.M. \& Davis, T.E., Supervision: Supervisees perceptions of their clinical supervision: A study of the dual role of clinical and administrative supervisor. Counsellor Education and Supervision, 46, 294-304, (2007)

24. Worthen, V., E., \& Isakson, R., L., The Supervision Outcomes Survey (SOS). In Falender \& Shafranske (2004). 